\title{
Dr. K. Mohan lyer (ed): Trapeziectomy, excision of the trapezium
}

\section{LAMBERT, Academic Publishing, July 2017, softcover, 68 pp, 35, $40 €$, ISBN: 978-620-2-00308-7}

\section{Pierre Kehr ${ }^{1}$}

Received: 6 May 2018 / Accepted: 20 May 2018 / Published online: 4 June 2018

(c) Springer-Verlag France SAS, part of Springer Nature 2018

In the introduction, the author reminds the reader that excision of the trapezium is considered to be a satisfactory procedure in patients with thumb base arthritis. A historical review of this surgery is presented.

The introduction is followed by an extensive anatomy chapter, which is beautifully illustrated.

Carpometacarpal osteoarthritis with its anatomopathological signs and stages is then described.

Arthrography of the joint performed by Graham H. Whitehouse in 1980 is introduced and exemplified with intraoperative images and X-rays.

The next chapter is dedicated to the surgical technique.

In the subsequent section, the author provides a very detailed clinical and etiological description of the operated cases. Twenty-six wrists in 18 patients were operated on. Postoperative views demonstrate the satisfactory nature of the results achieved.
Other therapeutical options are available, ranging from conservative treatments (physiotherapy, radiotherapy, splints, and infiltrations) to surgical procedures such as forage, tenodesis, arthrodesis, arthroplasty, and prosthetic replacement. In the discussion chapter the author explains why, in his view, the best option would be excision of the trapezium. The book concludes with a rich bibliography.

A brilliant and well-documented work that should be on the shelf of every surgeon specialised in hand surgery.

\section{Compliance with ethical standards}

Conflict of interest The author declares that he has no conflict of interest. 